\title{
O LÚDICO NA APRENDIZAGEM DE ALUNOS DE CURSOS TÉCNICO, GRADUAÇÃO E MESTRADO: RELATOS DE EXPERIÊNCIAS
}

\author{
EL LÚDICO EN EL APRENDIZAJE DE ESTUDIANTES DE CURSOS TÉCNICO, \\ GRADUACIÓN Y MAESTRO: RELATOS DE EXPERIENCIAS
}

\author{
THE LUDIC IN THE LEARNING OF THE STUDENTS OF THE COURSES \\ TECHNICAL, GRADUATION AND MASTER'S DEGREE: EXPERIENCES \\ REPORTED
}

Marcia Gorett Ribeiro GROSSI ${ }^{1}$

RESUMO: Os jogos e as brincadeiras são inerentes ao ser humano, por isso o lúdico é necessário no processo educativo. Processo esse que fica mais rico quando se vivencia diferentes formas de ensinar e de aprender. Nesta perspectiva, o objetivo deste estudo foi relatar as experiências sobre atividades lúdicas nas salas de aula, enquanto recurso pedagógico no processo de ensino e aprendizagem, dos alunos do Curso Técnico de Informática Industrial, do Programa Especial de Formação Pedagógica de Docentes e do Mestrado, todos esses do Centro Federal de Educação Tecnológica de Minas Gerais. Quanto à metodologia, optou-se pela pesquisa científica de natureza qualitativa. Em relação ao tipo de pesquisa, ela foi exploratória e descritiva acerca de relatos de experiências vivenciadas entre os anos de 2001 a 2015. Os resultados permitem afirmar que a sala de aula pode e deve ser lugar alegre e prazeroso independentemente do nível de ensino, onde os conteúdos das disciplinas podem ser apresentados aos alunos de forma alegre e cativante.

PALAVRAS-CHAVE: Educação. Lúdico. Jogos.

RESUMEN: Este estudio muestra que los juegos y los juguetes son inherentes al ser humano, por lo que el lúdico es mucho necesario en el proceso educativo. Proceso que se vuelve más rico cuando se viven distintas formas de enseñar y de aprender. En esta perspectiva, el objetivo del estudio fue relatar las experiencias sobre actividades lúdicas en las clases, en cuanto recurso pedagógico en el proceso de enseñanza y aprendizaje, de los estudiantes del Curso Técnico de Informática Industrial, del Programa Especial de Formación Pedagógica de Docentes y del Maestro, todos ellos del Centro Federal de Educación Tecnológica de Minas Gerais. En relación a la metodología, se optó por la investigación científica de naturaleza cualitativa. La investigación fue exploratoria y descriptiva acerca de relatos de experiencias vivenciadas entre los años 2001 a 2015. Los resultados permiten reconocer que la clase puede y debe ser un sitio alegre y con mucho placer, independientemente del nivel de

1 Centro Federal de Educação Tecnológica de Minas Gerais (CEFET-MG), MG - Brasil. Diretora administrativa financeira da Fundação de Apoio à Educação de Desenvolvimento Tecnológico de Minas Gerais e subcoordenadora do Mestrado em Educação Tecnológica do CEFET-MG. Doutora em Ciências da Informação pela Universidade Federal de Minas Gerais. E-mail: marciagrossi@terra.com.br 
enseñanza, donde los contenidos de las disciplinas pueden ser presentados a los estudiantes de manera alegre y seductora.

PALAVRAS CLAVE: Educación. Lúdico. Juegos.

ABSTRACT: The games and the jokes are inherent to the human being, therefore the ludic is necessary in the educational process. This process becomes richer when different ways of teaching and of learning are experimented. In this perspective, the objective of this study was to report the experiences of play activities in the classroom, as a pedagogical resource in the teaching and learning of students of the Course technician of the Informatics Industrial, of the Special Program of Pedagogical Training of Teachers and of the Master's degree. All this courses are of the Federal Center for Technological Education of Minas Gervais. As for the methodology, we opted for the scientific research of a qualitative nature. Regarding the type of research, it was exploratory and descriptive about reports of experiences lived between the years 2001-2015. The results indicate that the classroom can and should be cheerful and pleasant place and, regardless of the educational level, the subjects content can be presented to students in lively and engaging way.

KEYWORDS: Education. Ludic. Games.

\section{Introdução}

É fundamental vivenciar novas formas de ensinar e de aprender, e é isso que se espera nas práticas docentes. E uma das formas de ensinar é por meio de atividades lúdicas, como por exemplo, os jogos e as brincadeiras, que estão presentes no cotidiano de todas as pessoas, independente da faixa etária, seja na escola, na família ou no trabalho. Enfim, o ato de brincar é fundamental em nossas vidas, é parte integrante da vida do ser humano (DIAS, 2013).

Brincar é análogo a aprender, como enfatizam Dallabona e Mendes (2004, p.111): “[...] enquanto a aprendizagem é vista como apropriação e internalização de signos e instrumentos num contexto sociointeracionista, o brincar é a apropriação ativa da realidade por meio da representação". Dessa forma, o lúdico é um recurso dinâmico que pode conduzir a uma prática pedagógica prazerosa quando bem planejada. Por isso a atividade lúdica deve fazer parte do processo de ensino e aprendizagem e não ser apenas um passatempo sem um objetivo pedagógico. Tessaro e Jordão (2007, p.05) reforçam essa ideia ao afirmarem que “[...] as atividades lúdicas possuem objetivos pedagógicos específicos, para o desenvolvimento do raciocínio e aprendizado do aluno, em qualquer fase". 
Complementando, Oliveira (2002, p.160) lembra que “[...] ao brincar, afeto, motricidade, linguagem, percepção, representação, memória e outras funções cognitivas estão profundamente interligadas", ou seja, brincar facilita a aprendizagem. Somando se a isso, os jogos têm um forte caráter social, que ajudam os alunos não apenas na construção do conhecimento, mas também oferecem a eles a oportunidade de terem uma melhor percepção para o mundo real, onde a interação e a cooperação são fundamentais para o convívio na sociedade. Como realça Piaget (1975) ao ser citado por Wadswoth (1984):

O jogo lúdico é formado por um conjunto linguístico que funciona dentro de um contexto social; possui um sistema de regras e se constitui de um objeto simbólico que designa também um fenômeno. Portanto, permite ao educando a identificação de um sistema de regras que permite uma estrutura sequencial que especifica a sua moralidade. (WADSWORTH, 1984, p.44).

Quando se pensa no lúdico na educação é comum pensar na educação infantil. Porém, a ludicidade pode estar presente em diversos níveis de ensino, da educação infantil até os cursos de pós-graduação, pois qualquer processo de ensino e aprendizagem deve ser permeado por momentos de alegria, bem-estar e prazer.

Diante deste contexto, o objetivo deste estudo foi relatar as experiências sobre atividades lúdicas enquanto recurso pedagógico no processo de ensino e aprendizagem nas salas de aula dos alunos do Curso Técnico de Informática Industrial, do Programa Especial de Formação Pedagógica de Docentes e do Mestrado em Educação Tecnológica, todos esses do Centro Federal de Educação Tecnológica de Minas Gerais (CEFET-MG). Para isso, optou-se pela pesquisa científica de natureza qualitativa, cujo método consistiu-se em uma pesquisa descritiva acerca de um relato de experiência vivenciado entre os anos de 2001 a 2015, pelos discentes e um docente dos cursos acima.

A escolha deste tema se baseou na preocupação da autora desse artigo com suas práticas pedagógicas. Além disso, verificou-se que os estudos em relação à temática são poucos quando se trata de cursos técnicos, de graduação e pós-graduação, como pode ser comprovado por meio de uma consulta a Biblioteca Digital de Teses e Dissertações (BDTD) do Instituto Brasileiro de Informação em Ciência e Tecnologia (IBICT), realizada em 2015, para levantar o que tem sido produzido sobre o assunto nesses níveis de ensino. A seleção para a escolha dos trabalhos produzidos, teses e dissertações, guiou-se pelos seguintes passos: 
1) Seleção das pesquisas publicadas na biblioteca BDTD do IBICT. Foram utilizadas 14 combinações de palavras-chave: lúdico no ensino técnico; jogos no ensino técnico; jogos educativos no ensino técnico; brincadeiras no ensino técnico; lúdico na graduação; jogos na graduação; jogos educativos na graduação; brincadeiras na graduação; jogos no ensino superior; brincadeiras no ensino superior; lúdico na pós-graduação; jogos na pós-graduação; jogos educativos na pós-graduação e brincadeiras na pós-graduação.

2) Foram encontrados 3.517 registros, sendo que 1.345 apareceram mais de uma vez nas buscas, portanto, o número real de registros foi 2.172. Vale ressaltar que não foi feito um recorte temporal para essa busca.

3) Seleção dos trabalhos que se referem efetivamente ao tema pesquisado a partir da leitura do título, das palavras-chave, do resumo e, em alguns casos, do trabalho completo. Assim, dos 2.172 registros encontrados no segundo passo, 296 conversavam com a temática dessa pesquisa, mas abordavam níveis de ensino que não eram os tratados nesse estudo, e apenas 38 registros se referem efetivamente ao tema e níveis de ensino pesquisados.

Este resultado demonstra a necessidade de pesquisas acerca da temática, o que demonstra a relevância deste artigo.

\section{Referencial teórico: a educação e o lúdico}

O termo lúdico se origina do latim ludus que quer dizer jogo, brinquedo ou brincadeira. O lúdico está presente em todas as atividades que estimulam o prazer e a alegria, como explica Luckesi (1998):

Tomando por base os escritos, as falas e os debates, que tem se desenvolvido em torno do que é o lúdico, tenho tido a tendência em definir a atividade lúdica como aquela que propicia a "plenitude da experiência". Comumente se pensa que uma atividade lúdica é uma atividade divertida. Poderá sê-la ou não. O que mais caracteriza a ludicidade é a experiência de plenitude que ela possibilita a quem a vivencia em seus atos. (LUCKESI, 1998, p. 09) 
São vários os teóricos que corroboram com a importância do lúdico no processo de ensino e aprendizagem. Dentre eles, pode-se citar Piaget (1975) com seus estágios de desenvolvimento: sensório-motor, pré-operatório, operatório concreto e operatório formal. Esse autor estudou como ocorre a interação entre pessoa-objeto (brinquedo) no desenvolvimento humano; Vygotsky (1984) com sua teoria da zona de desenvolvimento proximal (ZDP), a qual representa o potencial de desenvolvimento de cada pessoa, demonstrou a importância do docente oferecer às crianças brincadeiras que estejam de acordo com a ZDP, pois para esse autor é no brinquedo que a criança aprende a agir numa esfera cognitiva, e Huizinga (2000), que apresenta o lúdico como componente promovedor do jogo, sendo que esses envolvem várias vertentes, desde a aceitação de regras até as manifestações de emoções como alegria, raiva, tensão, dentre outras.

Ainda Huizinga (2000) estabelece o lúdico como:

Uma atividade livre, conscientemente tomada como "não séria" e exterior à vida habitual, mas ao mesmo tempo capaz de absorver o jogador de maneira intensa e total. É uma atividade desligada de todo e qualquer interesse material, com a qual não se pode obter qualquer lucro, praticada dentro de limites espaciais e temporais próprios, segundo uma certa ordem e certas regras. (HUIZINGA, 2000, p. 16).

Mas, o que é educar e o que é ensinar? Rodão (2007, p. 95) sublinha que “[...] ensinar configura-se como a especialidade de fazer aprender alguma coisa, a que chamamos currículo, seja de que natureza for aquilo que se quer ver aprendido a alguém”. Já Sneyders (1996, p.36) vai além ao definir que “[...] educar é ir em direção à alegria”. Por isso, a escola pode ser um ambiente prazeroso, onde o ato de ensinar e o de aprender seja cercado de zelo e de alegria, cujas metodologias de ensino sejam pautadas por estratégias lúdicas. Embora isso não significa utilizar os momentos de brincadeiras como passatempo, o lúdico precisa ter um significado pedagógico, tornando a aprendizagem motivadora, desafiadora e significativa.

A respeito da aula se tornar significativa, Roloff (2010, p.03) lembra que o “[...] lúdico é de extrema importância, pois o professor além de ensinar, aprende o que o seu aluno construiu até o momento, condição necessária para as próximas aprendizagens". Porém, “[...] desenvolver o lúdico no contexto escolar exige que o educador tenha uma fundamentação teórica bem estruturada" como afirma Dias (2013, p. 04). Dessa forma, os educadores precisam ter cuidado ao utilizá-lo, como alertam Tessauro e Jordão (2007): 
Ao tratar do tema "jogos em sala de aula", deve-se levar em consideração muitos aspectos, a idade dos alunos, seus gostos e preferências, o material disponibilizado, a metodologia de ensino adotada pelo professor e muitas outras características que irão influenciar nos resultados das atividades desenvolvidas. (TESSARO e JORDÃO, 2007, p.07).

A experiência que o lúdico oferece nos processos de ensino e aprendizagem passa por várias vertentes além da construção do conhecimento de um determinado conteúdo, tais como a socialização, as influências culturais e também as questões emocionais. Pois, durante um jogo os alunos precisam respeitar regras, trabalhar em equipes (dependendo da atividade), esperar a sua vez e lidar com as perdas (dependendo do resultado), aceitar e valorizar a vitória dos outros, aprendendo a lidar com seu emocional.

Embora os teóricos tenham estudado sobre o lúdico na educação infantil, não é somente nessa modalidade de ensino que se pode utilizar da ludicidade, mas em qualquer modalidade, nos ensinos fundamental e médio, nos cursos técnicos, no ensino superior e até mesmo na pós-graduação, como lembra Roloff (2010, p. 02) “[...] o lúdico pode trazer à aula um momento de felicidade, seja qual for a etapa de nossas vidas, acrescentando leveza à rotina escolar e fazendo com que o aluno registre melhor os ensinamentos que lhe chegam, de forma mais significativa".

O que muda é a forma de lidar com o lúdico em cada fase da aprendizagem e em cada fase etária de um aluno. O que antes era divertido para uma criança, pode ser chato para um adolescente e cansativo para um aluno adulto. Por exemplo, o adolescente precisa de desafio, e o adulto necessita relacionar suas experiências com seus conhecimentos prévios. Assim, o docente deve escolher estratégias lúdicas coerentes com a idade do aluno e ao mesmo tempo com os objetivos pedagógicos da disciplina, de tal maneira que consiga envolver seus alunos e motivá-los a participar das brincadeiras.

Porém, Rodoff (2010) alerta:

O professor deve usar a ludicidade como importante fator de mediação e integração do aluno com a realidade; o aluno não aprende somente na escola. Se o conteúdo não for assimilado, pelo menos em parte, e não for ligado a nenhuma estrutura cognitiva, cairá no esquecimento, não terá nenhuma relevância. (ROLOFF, 2010, p.03).

\section{Relatos das experiências}


As experiências com o lúdico, utilizado como recurso pedagógico, durante os anos de 2001 a 2015, foram vivenciadas no CEFET-MG. Participaram um total de 547 alunos, assim distribuídos: 388 do Curso Técnico de Informática Industrial: disciplinas Laboratório de Eletrônica Geral, Laboratório de Eletrônica Digital e Laboratório de Eletrônica Industrial; nove alunos do Programa Especial de Formação Pedagógica de Docentes: disciplina Prática de ensino e 150 alunos do Mestrado em Educação Tecnológica, disciplinas: As novas tecnologias em ensino e aprendizagem na educação tecnológica, Tópicos Avançados em Educação tecnológica: as novas Tecnologias e o Ciberespaço, a Ciberpolítica e a Ciberdemocracia e Educação a distância.

Nestas experiências foi envolvida apenas uma professora, a qual lecionava as disciplinas listadas acima, que foi responsável pela concepção e confecção dos protótipos dos jogos, bem como pelo acompanhamento das atividades lúdicas em suas salas de aula.

\section{Relato da experiência com os alunos do curso técnico}

Enquanto professora de uma área tão hard, como a eletrônica, a autora do artigo elaborou alguns jogos pedagógicos envolvendo conhecimentos dessa área que fossem capazes de unir conhecimento e entretenimento; enquanto os alunos estivessem jogando estariam exercitando suas funções mentais e intelectuais. O objetivo era que seus alunos, por meio dos jogos, pudessem reforçar os conteúdos aprendidos e serem capazes de: aceitar e respeitar regras, trabalhar em equipe, lidar com frustrações, ser organizados e disciplinados. Além disso, para participarem dos jogos, os alunos precisaram desenvolver habilidades como a atenção e a concentração. Enfim, que os jogos pudessem contribuir para o desenvolvimento de suas criatividades, sociabilidade e as inteligências múltiplas. De acordo com Dias (2013):

O lúdico proporciona além de situações prazerosas, o surgimento de comportamentos e assimilação de regras sociais. Ajuda a desenvolver seu intelecto, tornando claras suas emoções, angústias, ansiedades, reconhecendo suas dificuldades, proporcionando assim soluções e promovendo um enriquecimento na vida interior da criança. (DIAS, 2013, p.15). 
Desse modo, a idealização dos protótipos dos jogos para os seus alunos foi fruto da observação feita por ela de seus filhos brincando. A partir dessa observação, a docente desenvolveu três jogos. Ao utilizá-los, ela teve o cuidado de não perder o objetivo principal de uma atividade docente, conforme enfatizam Pacho, Aguiar e Leite (2012) ao afirmarem que o recurso pedagógico é o meio para atingir um fim, e este é a aprendizagem. Portanto, os professores precisam estar atentos a respeito da dimensão pedagógica de seus atos.

Antes de apresentar os jogos que foram desenvolvidos, é importante ressaltar que só existiu um modelo de cada um, e com o objetivo unicamente educacional, nunca houve nenhuma comercialização financeira. Os três jogos foram:

\section{Primeiro jogo didático: a corrida dos elétrons}

Esse jogo foi desenvolvido para as aulas de laboratório de eletrônica geral dos alunos do curso Técnico em Informática Industrial. Em cada turma tinha 12 alunos, que para participar do jogo foram divididos em três grupos. Cada um deles representava três áreas trabalhadas na disciplina: Eletricidade (grupo vermelho), Instrumentos e componentes (grupo verde) e Eletrônica Geral (grupo azul), como pode ser verificado na figura 01 .

Figura 01: Tablado do Jogo didático: A corrida dos elétrons.

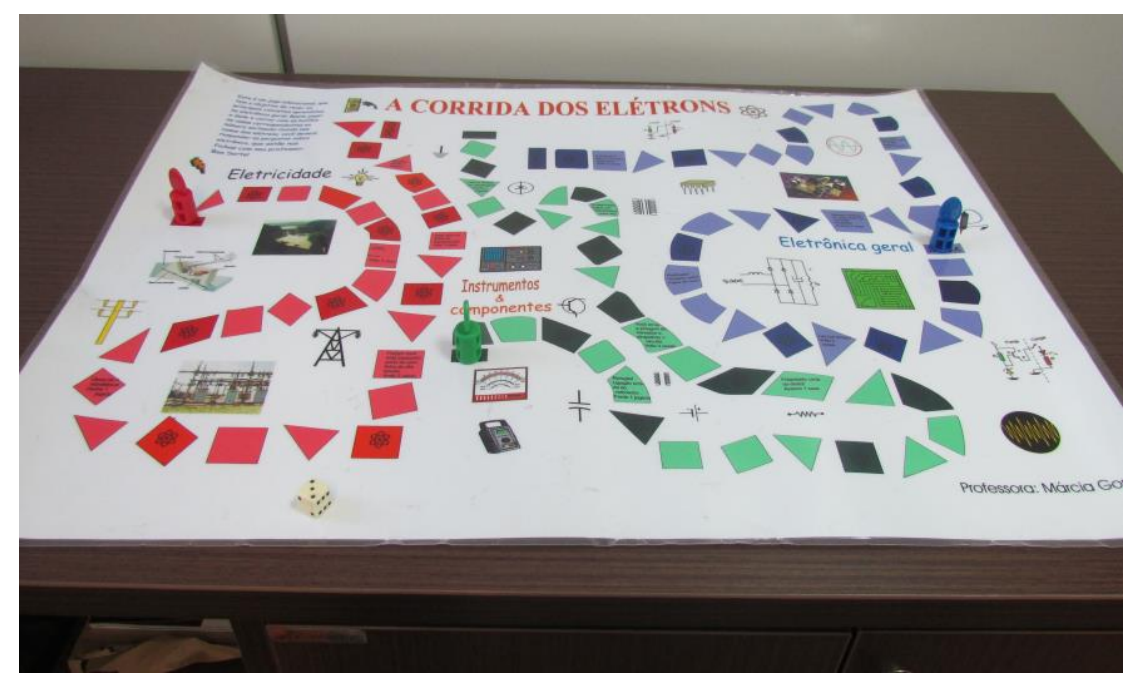

Fonte: Arquivo pessoal. 
A lógica do jogo era simples: quando um grupo lançava o dado, avançava-se o peão pelas casas correspondentes ao número sorteado no dado. Quando o peão caía na casa marcada elétrons, o grupo precisava responder a uma pergunta sobre os conteúdos da disciplina. Essas perguntas estavam em fichas que ficavam com a professora durante os jogos, como apresentado na figura 02. No decorrer do percurso havia algumas casas que continham afirmativas verdadeiras e, se o peão caísse nessas casas, o grupo podia avançar determinadas casas, mas também havia casas com afirmativas falsas, e nesse caso o grupo tinha que voltar determinadas casas.

Figura 02: Fichas com perguntas do jogo corridas dos elétrons.

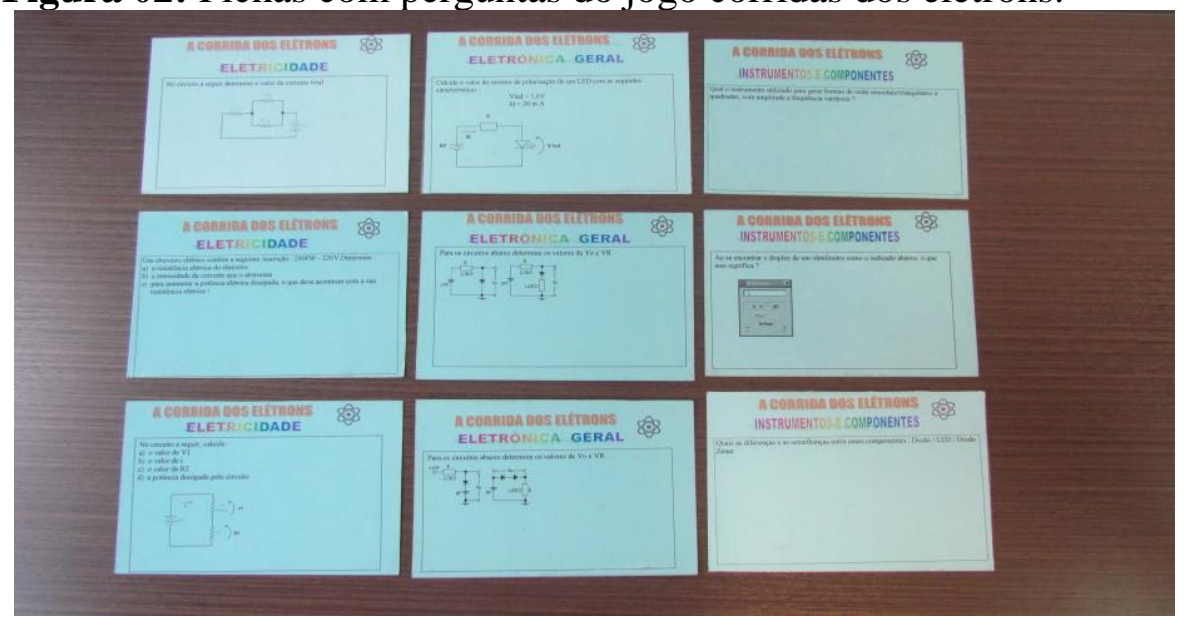

Fonte: Arquivo pessoal.

No final, o grupo que chegasse primeiro na última casa, ganhava o jogo. Mas independentemente de quem ganhasse, todos os grupos no final da aula precisavam responder às perguntas das fichas, independente se durante o jogo tivessem caído ou não na casa dos elétrons. A nota que os alunos recebiam era dada de acordo com suas respostas, e não se tinham vencido o jogo, embora o grupo que chegava primeiro na última casa ganhasse alguns brindes, como lápis, canetas ou bombons.

\section{Segundo jogo didático: Dominó}

Esse jogo foi desenvolvido para as aulas de laboratório de Eletrônica Digital dos alunos do Curso Técnico em Informática Industrial. Era um jogo simples, como qualquer dominó, formado por peças retangulares de dois quadrados congruentes colocados lado a lado. Em um quadrado havia uma resposta de uma questão sobre o 
conteúdo da disciplina. No outro, uma pergunta cuja resposta estava em outra peça (figura 03). Cada turma era composta por 12 alunos que eram divididos em três grupos. Cada grupo jogava de modo independente dos outros grupos.

Nesse caso, a competição era entre os quatro alunos de um mesmo grupo. Cada aluno recebia suas peças aleatoriamente e viradas para baixo. O objetivo era baixar todas as peças. Para isso acontecer, eles precisavam conhecer bem o conteúdo da disciplina. Como no outro jogo, sempre havia brindes para quem terminasse primeiro. Reforça-se aqui que a pontuação não estava atrelada ao fato de quem terminasse antes, o importante era montar as peças corretamente. Porém, como combinado com os alunos, quem terminasse primeiro ganhava pequenos brindes.

Figura 03: Jogo de dominó.

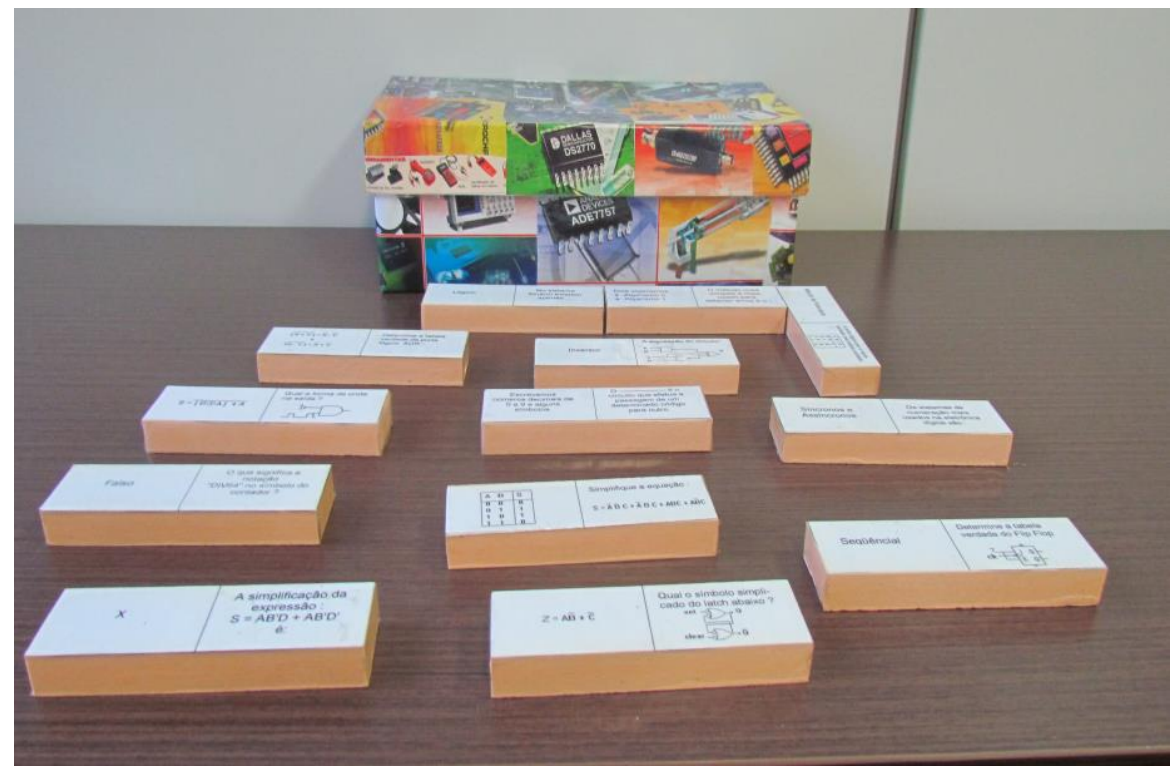

Fonte: Arquivo pessoal

Terceiro jogo didático: A Corrida dos SCRs

Esse jogo foi desenvolvido para as aulas de laboratório de Eletrônica Industrial dos alunos do curso Técnico em Informática Industrial (figura 04). É importante ressaltar que para elaborar o layout do tabuleiro desse jogo, a autora se baseou em um jogo da Grow intitulado Jogo Rápido, fazendo as devidas alterações para a área da eletrônica e também nas regras do jogo.

Como nas outras disciplinas, a turma era composta por 12 alunos. Para esse jogo, a turma foi dividida em dois grupos: verde e rosa. Cada grupo precisava responder 10 
perguntas que estavam em fichas que ficavam com a professora durante os jogos. A cada resposta certa o botão avançava para uma casa de um SCR que estava do lado de um ponto positivo. Se a resposta estivesse errada, o botão avançava para uma casa um SCR que estava do lado de um ponto negativo. Se na próxima pergunta eles acertassem, voltavam para o número menos negativo. Ganhava o grupo que chegasse primeiro no SRC correspondente ao ponto 10 . O grupo vencedor ganhava brindes, mas as notas eram de acordo com as respostas das perguntas feitas durante o decorrer do jogo.

Figura 04: Jogo Corrida dos SCRs.

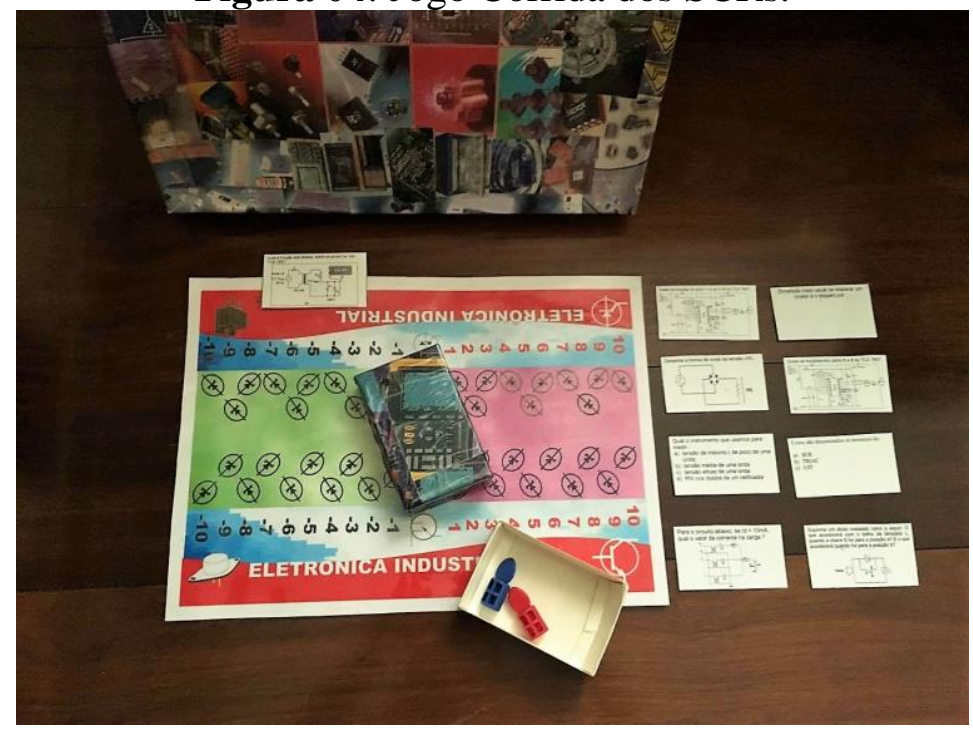

Fonte: Arquivo pessoal.

\section{Relato da experiência com os alunos da graduação e do mestrado}

$\mathrm{Na}$ graduação e nos cursos de mestrado, a docente leciona em disciplinas da área da Educação, e dentre suas estratégicas pedagógicas foram escolhidas três para serem apresentadas aqui:

\section{Café com filme}

O uso de filmes como recurso didático exige um planejamento cuidadoso, que começa com a escolha destes. É preciso uma história cujo enredo esteja relacionado aos conteúdos estudados. Aqui nessa experiência, a professora surpreendia seus alunos com o título do filme, pois eles só ficam sabendo na hora da exibição do filme. Porém, antes de começar, era feito um comentário sobre os conteúdos pedagógicos presentes no 
enredo, e a professora entregava para os alunos algumas questões que deveriam ser observadas durante o filme para prepará-los para um debate no final da exibição.

Por exemplo, na disciplina "As novas tecnologias em ensino e aprendizagem na educação tecnológica", um dos conteúdos é o processo de virtualização, e para tratar desse tema é utilizado o livro do Pierre Lévy: $O$ que é o virtual? Assim, era feito a leitura e debate sobre o livro e como complemento os alunos assistiam o filme A Cela. Antes da exibição do filme eles recebiam as questões para serem discutidas no final da exibição (figura 05).

Figura 05: Ficha com temas sobre o filme A cela.

No filme A Cela o processo de virtualização não acontece exatamente como a definição de Lévy, portanto:

1) Identifique os três sentidos da virtualidade presentes no filme.

2) Nesse filme, a virtualização elimina os espaços já existentes?

3) E as fronteiras do real? Deixam de existir no virtual?

4) Como acontece o efeito Moebius no filme? Dê exemplos.

Fonte: Arquivo pessoal.

Outro filme usado nas turmas da graduação e do mestrado foi a vida da Temple Grandin, a história verídica de uma autista que atualmente é professora de Ciência Animal da Universidade do estado do Colorado e especialista em manejo de bovinos, métodos de abate humanitário e bem-estar animal. O que mais chamou atenção nessa história foi o talento da Temple Grandin em pensar diferente, pensar por imagens e fazer a conexão entre estas. O filme é utilizado para a turma do mestrado na disciplina “As novas tecnologias em ensino e aprendizagem na educação tecnológica”, devido ao fato de que uma das unidades de ensino dessa disciplina aborda as neurociências na sala de aula; especificamente, como cada pessoa utiliza o cérebro de uma maneira diferente para pensar e aprender, fato que precisa ser considerado nas escolhas das nossas práticas pedagógicas.

Por esse mesmo motivo, esse filme também é usado como estratégia pedagógica para a turma da graduação na disciplina "Prática de ensino e estágio supervisionado", para alertar os futuros professores sobre a importância de compreender as habilidades e limitações de cada aluno. Para que esse momento com seus alunos se tornasse ainda mais atrativo e aconchegante, foi lançado o café com filme. Uma semana antes da data 
do filme é feita uma lista onde cada aluno e a professora escrevem o que será levado para o café, que acontece uma vez por semestre em cada turma.

\section{Caça palavras}

Foi elaborado um caça palavras para as turmas, de acordo com os conteúdos de cada disciplina. Para tal, foi utilizando 0 site free: <http://www.crosswordpuzzlegames.com>. Um exemplo de um caça palavra desenvolvido para uma turma do mestrado que estava estudando o tema virtualidade pode ser visto na figura 06. Percebe-se que para conseguir preencher o caça palavras é preciso responder 14 questões sobre o conteúdo da disciplina.

Figura 06: Exemplo de um caça palavra.

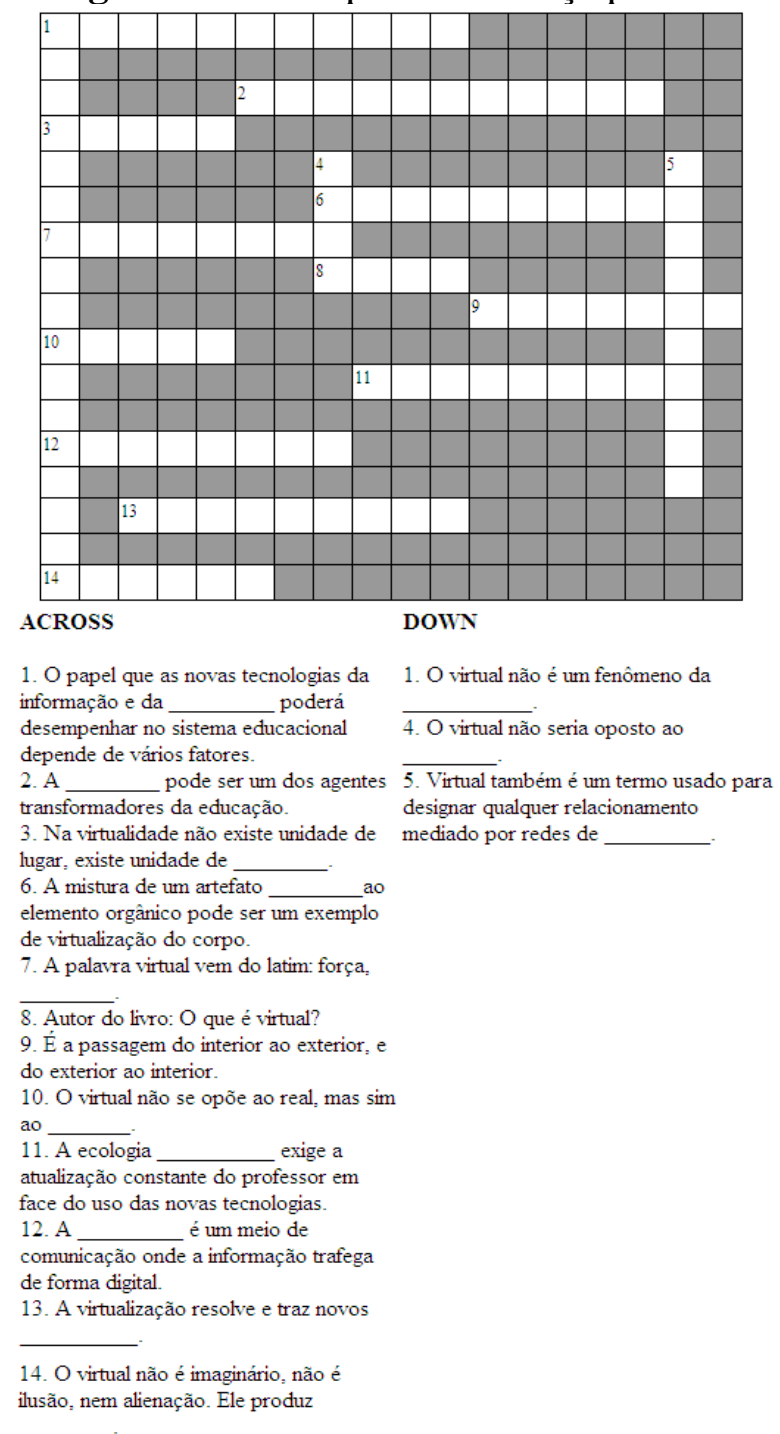

Fonte: Arquivo pessoal. 
Caixa de brinquedos e caixa de ferramentas

Para Alves (2004), a vida não se justifica pela utilidade. Ela se justifica pelo prazer e pela alegria. Também Chalita (2013, online) reforça: “[...] é preciso redescobrir a caixa de brinquedos. A de ferramentas é útil, mas não preenche o essencial”.

A ideia é que toda criança tem uma caixa de brinquedo com suas bolas, bonecas, carrinhos, enfim, com seus brinquedos. À medida que cresce vai adquirindo outra caixa, a caixa de ferramentas. Nessa segunda caixa coloca seus cadernos, livros e, com o tempo, os seus equipamentos de trabalho. Aos poucos a caixa de brinquedo é substituída pela caixa de ferramentas. Claro que não se pode passar toda a vida apenas com a caixa de brinquedos, mas também não se pode viver sem ela. Mas é isso que a maioria das pessoas fazem, tornando, às vezes, a vida muito pesada. A caixa de brinquedo é aquela que desliga as pessoas da rotina do trabalho, que as fazem sonhar e descansar a alma.

Dessa forma, a professora decidiu materializar essa história: a cada início de semestre letivo, quando começavam as aulas com uma nova turma, não importava se era do técnico, da graduação ou do mestrado, ela contava essa história e levava duas caixas (figura 07): uma com objetos que remetem a ferramentas de trabalho, por exemplo, calendário, relógio, canetas, grampeador, post it, dentre outros. E a outra com objetos que sugerem lazer, como, por exemplo, peteca, livros de poesias, alguns joguinhos, massinha de modelar, bonés, bolinha de tênis, dentre outros, e faz-se o sorteio das caixas entre os alunos.

Figura 07: Caixas de brinquedo e de ferramenta.

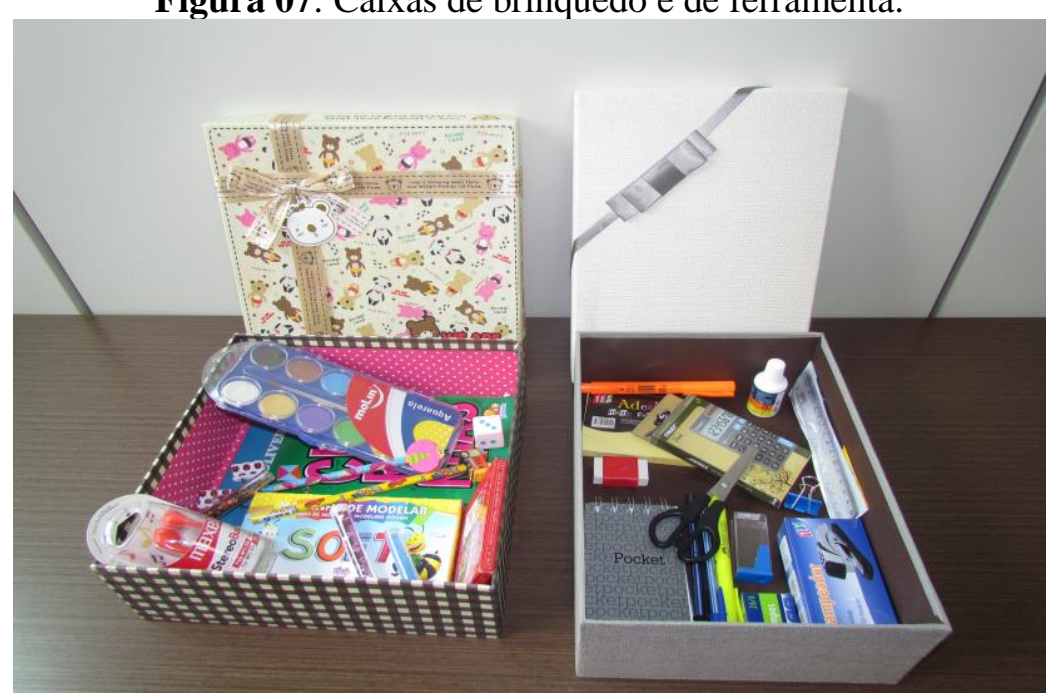

Fonte: Arquivo pessoal. 


\section{Resultados e análises}

\section{Das experiências com os alunos do curso técnico}

Esta experiência trouxe como principal resultado o aumento do interesse dos alunos pelos conteúdos das disciplinas. Percebeu-se também durante as atividades nos laboratórios valores como respeito, companheirismo, cooperação, tolerância, dentre outros. Tudo isso envolvido em uma esfera cognitiva, que culminou com melhoria nos resultados e avaliações dos alunos. A seguir, depoimentos de alunos que participaram desses jogos:

\footnotetext{
"Aos 16 anos, tendo que encarar uma realidade pesada de uma escola de alto nível e com uma carga horária extremamente puxada de Ensino Médio e Curso Técnico ao mesmo tempo, um pouco de leveza era tudo que nós, alunos, gostaríamos. Ainda mais se tratando de disciplinas pesadas como Eletrônica Geral e Digital. As aulas práticas ao longo do semestre terminaram com surpreendentes avaliações em forma de jogos. Estimulante, motivador $e$ extremamente didático. Ainda mais em um curso de Informática em que a maioria dos alunos tem, por natureza, um perfil competitivo. Ninguém gosta de perder e, isto motivava a estudar e se preparar para ser o melhor. Um prelúdio do mercado de trabalho que encararíamos mais tarde. Jamais esquecerei aquelas lições de eletrônica e de vida".

"A professora é dinâmica, sempre traz novas ideias para nossas aulas de eletrônica. Assim, a matéria fica mais leve e fácil de ser compreendida. $O$ nosso curso tem várias turmas, mas a professora não leciona para todas, por isso, sempre no começo do ano tem a expectativa de quais turmas vai ter aula com ela, que felicidade quando caímos em sua sala de aula e os alunos que não tinham essa sorte ficam até bravos e tentavam trocar de sala, eu tive a sorte de ser seu aluno e participar dos jogos que ela fazia".
}

\section{Das experiências com os alunos da graduação e do mestrado}

No que se refere à atividade café com filme, pode-se afirmar que os resultados foram positivos. Percebeu-se que as turmas ficaram muito animadas e envolvidas durante todo o processo, que começa com a organização do café e termina com as discussões sobre o filme. É gratificante observar as relações que os alunos conseguem fazer entre os enredos dos filmes e os conteúdos das disciplinas. Os filmes ajudaram a esclarecer os conteúdos apresentados na aula teórica, e o café proporcionou um ambiente aconchegante e prazeroso. 
Por isso, a professora procura ficar atenta aos filmes que assiste, tentando enxergar neles possibilidades didáticas para suas aulas, e já possui uma estante de filmes para seus diversos conteúdos programáticos, tais como: Entre os muros da escola; A cela; $O$ clube do imperador; Alexandria, Escritores da liberdade; A onda; Sociedade dos poetas mortos e Coach Carter - Treino para a Vida. A seguir, depoimentos de alunos que participaram dessa atividade:

\begin{abstract}
"Nessas aulas eu aprendi a ser uma professora mais humana, carinhosa e reflexiva. Em suas aulas, além do conteúdo programado para a pós-graduação, sempre tem um momento de descontração e reflexão como o café com filme onde temos a oportunidade de alimentar o corpo físico e a mente com novas ideias e conceitos, saindo assim da zona de conforto e pensamento massificado, linear que a mídia e o mundo nos apresentam. Neste ambiente sentíamos a vontade de expressar nosso pensamento, análise e crítica sobre o filme além de fazer o link deste com a disciplina em curso".
\end{abstract}

"O café com filme é um dos momentos de grande diferencial. Desde a escolha do filme pela professora, vinculado com a temática da disciplina até a delicadeza na organização do café, em que todos os alunos são convidados a contribuir na organização. O filme escolhido foi A Cela e após a exibição fizemos uma discussão muito rica sobre o virtual e o real. Toda a discussão baseada no filme e em leituras realizadas previamente".

"Os cafés com Filme, enquanto prática pedagógica apresentaram-se para mim como uma excelente oportunidade de desenvolvimento acadêmico e cultural, ao trazer para a sala de aula temas de estudos em uma versão cinematográfica, que proporciona uma visão sobre o assunto que vai além daquela obtida através de uma apresentação tradicional. O envolvimento de toda classe em um ambiente amigável, que se inicia antes mesmo da sessão, com a própria mobilização dos alunos na organização e preparativos para o café, e não termina com um simples debate após apresentação do filme, visto que o assunto continua com outras reflexões nas semanas posteriores ao café”.

Sobre a atividade caça palavras, pode-se afirmar que foi uma atividade que ajudou os alunos a pensar sobre os conteúdos da disciplina de uma forma diferente e divertida, o que confirma as opiniões de Dallabona e Mendes (2004), ao pontuarem que aprender a pensar diferente é mais importante do que memorizar fatos e dados a respeito do assunto. Nessa atividade observou-se que os alunos desenvolveram a atenção, a concentração, fixaram conteúdos e estimularam a percepção visual. Essas observações corroboram as ideias de Almeida (2014), ao destacar que: 
O caça - palavras atuam em todo o córtex e a principal atuação dele é na memória. A memória de curto prazo vai ser fundamental no exercício com o caça palavras, por que ela serve para alimentar a nova realidade. Quando falamos de memória temos a impressão de coisas que temos que recordar, mas além delas tem também a que estou vivendo aqui e agora, saindo da memória de longo prazo para a de curto prazo. (ALMEIDA, 2014, online).

Alguns depoimentos de alunos que participaram dessa atividade:

"E para reforçar ainda mais aquele assunto importante, um pouquinho de competitividade em prol da diversão, não fazia mal a ninguém, pelo contrário, ao encontrarmos no caça palavras o conceito de um assunto estudado, não havia mais memória que falhasse, pelo estudo e pelo momento vivido!".

"Ensinar não é transmissão de conhecimento. É processo. Processo no qual atuam dialogicamente aluno e professor, sendo este o responsável pela condução do aprendizado. Tendo como objetivo tornar esse processo mais produtivo e dinâmico nossa professora traz o lúdico para sua sala de aula, faz uma ruptura do tradicional convencional - habitual contribui com um novo olhar para a teoria anteriormente exposta, em um ambiente descontraído, efetivamente, ampliando nossas sinapses".

Sobre a caixa de brinquedos, pode-se verificar que os alunos ficaram a princípio curiosos, e logo em seguida começam a refletir sobre suas práticas diárias, sobre suas responsabilidades, suas escolhas e sobre a importância de recuperar a energia de um dia de trabalho e/ou estudo para conseguirem manter a saúde mental e física. Os alunos relatam que a partir da analogia das duas caixas começaram a mudar suas rotinas de forma a manter o equilíbrio e a minimizar o stress diário. Alguns depoimentos de alunos que participaram dessa atividade:

"Uma experiência interessante foi quando a professora chegou à sala
com duas caixas de presente: uma chamada de brinquedo e outra de
ferramentas, cheia de mistério para o final da aula, dizendo que iria
sortear entre nós aluno. Todos como crianças naquele momento,
cheios de expectativa que seu número de chamada fosse sorteado e
querendo é claro, a de brinquedos. Particularmente fui uma das
premiadas com a caixa de ferramentas, que caixa! Bloco de
anotações, canetas de todas as cores, lápis, grampeador, clips,
corretivo, borracha e outros artigos de papelaria, era tanta
ferramenta. Tudo que uma mestranda com a cabeça cheia de ideias e
dúvidas precisava utilizar para começar seu projeto e dar início à sua
dissertação. A caixa de ferramentas era figurativa e funcional.
Durante o mestrado anotei, colori ideias, apaguei outras, grampeei
informaçôes, passei a lápis sugestôes, outras a caneta, e nas 
dificuldades usei o corretivo mesmo. Foi extremamente inspiradora essa caixa. De vez em quando olho pra ela, ainda com alguns objetos, outros já se foram pelo uso, mas sempre pensando que a vida em família, acadêmica, profissional, religiosa ou em outra esfera, necessita de diversas ferramentas para ser construída e reciclada. Foi muito gratificante e enriquecedora a experiência de ser aluna e orientanda dessa. Obrigada pela sua dedicação e exemplo".

"Um momento que trouxe essa leveza para a aula foi apresentação das caixas de "brinquedos" e de "ferramentas". Partindo da leitura de um texto de Rubem Alves "A caixa de ferramentas" a professora nos apresentou a importância do "brincar" e do "trabalhar" e que devemos carregar sempre duas caixas: uma caixa de "ferramentas", que nos remete ao nosso trabalho e a nossa produção, e a caixa de "brinquedos" que não devemos abrir mão porque já não somos mais crianças, devemos mantê-la para que em alguns momentos possamos nos entregar a ela, em momentos de descontração e de prazer, que todo ser humano precisa. No final da aula a professora faz o sorteio de caixas, e dentro delas estão: as "ferramentas" para nós alunos da academia: calculadora, calendário, canetas, régua, clips; e na caixa de brinquedos: massinha, giz de cera, cola colorida, tinta. No sorteio fui contemplada com a caixa de ferramentas, mas a professora sugeriu que eu não me esquecesse dos momentos do "brincar".

"As aulas ministradas por essa professora são marcadas pela dinamicidade e por atividades que estimulam os alunos a pensarem além do que está sendo proposto nas disciplinas. Um exemplo disso é a dinâmica realizada sobre a caixa de brinquedo e de ferramentas. A atividade, além de empolgante - pois todos ficam eufóricos na expectativa por saber quem será o contemplado e, também, curiosos em saber o que há dentro das caixas - é ainda uma atividade que nos leva a refletir sobre a importância do equilíbrio em nossas ações e em nossos hábitos cotidianos. Particularmente, tive a oportunidade de ser contemplada duas vezes nessa atividade. Em um semestre fui sorteada com a caixa de ferramentas e no segundo com a caixa de brinquedo. Em ambos os momentos, além de feliz por ter sido a contemplada, fiquei também pensativa. Recordo-me que ao receber as caixas, passei um tempo analisando os meus hábitos e me questionando o que poderia fazer para proporcionar equilíbrio entre os momentos de lazer e de trabalho. E, ainda hoje, faço uso da analogia das caixas quando quero repensar certas atitudes cotidianas".

Em síntese, pode-se observar que a participação dos alunos em todas as atividades lúdicas propostas ocorreu de maneira muito satisfatória. Percebeu-se nos depoimentos dos alunos, não apenas nos que estão registrados nesse artigo, mas de todos que já participaram das atividades apresentadas aqui, que a força dessas atividades estava no entusiasmo e na vontade de participar. $\mathrm{O}$ aprender aconteceu naturalmente, foi ao mesmo tempo o objetivo e a consequência. O clima de coletividade também foi perceptível e as experiências vividas durante essas aulas foram lições de vida e oportunidade de muitas aprendizagens. 
Outra observação que vale trazer aqui foi que o foco dos processos de ensino e aprendizagem saiu do professor, que se comportou como o mediador das interações nesses processos, ou seja, gerenciou a interação entre seus alunos num espaço de construção, de valorização e respeito, onde a aprendizagem aconteceu entre sorrisos.

\section{Considerações finais}

Os jogos e as brincadeiras são inerentes ao ser humano, por isso o lúdico é necessário no processo educativo, e ao utilizá-lo na sala de aula não significa que está se descuidando da seriedade dos conteúdos ministrados, é simplesmente uma maneira diferente de ensinar e de aprender, que proporciona ao aluno um olhar mais tangível do mundo.

Acredita-se, então, que a missão de um educador vai além da transmissão dos conteúdos programáticos de uma disciplina, é também ter a preocupação com formação humana dos alunos, com os exemplos que se passa para eles dentro e fora da sala de aula. Pode-se afirmar que a responsabilidade do professor com seus alunos assume uma dimensão ética e de cuidado. Porém, é preciso lembrar que o conhecimento não é produto, é vida.

As elaborações de cada uma das atividades apresentadas nesse artigo não foi um processo simples, foi exigida disposição para muito trabalho, e como lembram Dallabona e Mendes (2004, p.110) “[...] educar ludicamente não é jogar lições empacotadas para o educando consumir passivamente. Educar é um ato consciente e planejado". E, como já ressaltado anteriormente, foi dedicado muito tempo a tal projeto, desde as concepções dessas atividades até elas ficarem prontas, e algumas vezes também foram necessários recursos financeiros da própria docente, pois tudo foi feito sem nenhum apoio material.

Mas esse esforço foi recompensado pelo entusiasmo que se percebeu nos alunos durante essas atividades. Foi encantador perceber a motivação e a alegria dos alunos enquanto eles discutiam naturalmente os conteúdos das disciplinas de uma maneira tão tranquila e natural. Eles tinham prazer em participar e aprendiam espontaneamente. Além da assimilação de novos conceitos e da construção do conhecimento, por meio das atividades lúdicas, o aluno desenvolve relações sociais com seus colegas, favorecendo o seu desenvolvimento integral. 
Por isso, pode-se afirmar que a sala de aula pode e deve ser um lugar alegre e prazeroso, e, independentemente do nível de ensino, os conteúdos das disciplinas podem ser apresentados aos alunos de forma alegre e cativante, de tal forma que a rotina escolar se torne leve.

Finalizando, pode-se concluir que a união entre a educação e o lúdico ultrapassa uma tarefa escolar, é uma oportunidade de muita aprendizagem que vai além dos conteúdos ministrados, é uma aprendizagem para a vida.

\section{REFERÊNCIAS}

ALMEIDA, Maria Aparecida de. Os benefícios para quem faz palavras cruzadas e caça palavras. 2014. Disponível em: <http://br.blastingnews.com/lazer/2014/09/osbeneficios-para-quem-faz-palavras-cruzadas-e-caca-palavras-00128938.html>. Acesso em: 03 Fev. 2016.

ALVES, Rubens. A caixa de brinquedos. 2004. Disponível em: <http://www1.folha.uol.com.br/folha/sinapse/ult1063u877.shtml>. Acesso em: 03 fev. 2015.

CHALITA, Gabriel. É preciso redescobrir a caixa de brinquedos. A de ferramentas é útil mas não preenche o essencial. 2013. Disponível em:

<https://twitter.com/gabriel_chalita/status/381736926853615616>. Acesso em: 03. Fev. 2015.

DIAS, Elaine. A importância do lúdico no processo de ensino-aprendizagem na educação infantil. Revista Educação e Linguagem, V.7, n.1, p.1-16, 2013. Disponível em: 〈http://www.ice.edu.br/TNX/index.php?sid=266>. Acesso em: 03 fev. 2016.

DALLABONA, Sandra Regina; MENDES, Sueli Maria. Lúdico na educação infantil: Jogar, brincar, uma forma de educar. Revista de divulgação técnico-científica do ICPG, v.1, n.2, p.107-112, 2004.

HUIZINGA, Johan. Homo Ludens: O jogo como elemento da cultura. São Paulo: Perspectiva, 2000.

LUCKESI, Cipriano Carlos. Desenvolvimento dos estados de consciência e ludicidade 1998. Disponível em: <ww.luckesi.com.br/textos/lucididade_desenvolvimento_dos_estados.doc>. Acesso em: 05 fev. 2016.

OLIVEIRA, Zilma Ramos de. Educação infantil: fundamentos e métodos. São Paulo: Cortez, 2002.

PACHO, C. L.; AGUIAR, M.N.; LEITE, L.S. Tecnologia educacional: descubra suas possibilidades na sala de aula. 7. ed. Petrópolis, RJ: Vozes, 2012. 
PIAGET, Jean. A formação do símbolo na criança. Rio de Janeiro: Zahar, 1975.

ROLOFF, Eleana Margarete. A importância do lúdico em sala de aula. 2010. Disponível em:

<http://ebooks.pucrs.br/edipucrs/anais/Xsemanadeletras/comunicacoes/EleanaMargarete-Roloff.pdf>. Acesso em: 05 fev. 2016.

SNEYDERS, Georges. Alunos felizes. São Paulo: Paz e Terra, 1996.

TESSARO, Josiane Patrícia; JORDÃO, Ana Paula Martinez. Discutindo a importância dos jogos e atividades em sala de aula. 2007. Disponível em: <http://www.psicologia.pt/artigos/textos/A0356.pdf>. Acesso em 03 fev. 2016.

VYGOTSKY, L. S. A formação social da mente. São Paulo: Martins Fontes, 1984.

WADSWORTH, Barry. Jean Piaget para o professor da pré-escola e $\mathbf{1}^{\mathbf{0}}$ grau. São Paulo: Pioneira, 1984.

\section{Como referenciar este artigo}

GROSSI, Marcia Gorett Ribeiro. O lúdico na aprendizagem de alunos de cursos técnico, graduação e mestrado: relatos de experiências. Revista Ibero-Americana de Estudos em Educação, Araraquara, v. 12, n. 3, p. 1689-1709, jul-set/2017. Disponível em: <http://dx.doi.org/10.21723/riaee.v12.n.3.2017.8510>. E-ISSN: 1982-5587.

Submetido em: 09/04/2016

Aprovação final em: 11/05/2017 